\title{
Contribuições da Teoria Histórico-cultural para a prática de estágio supervisionado em Psicologia Escolar
}

\author{
Contributions of Historical-cultural Theory to \\ a supervised internship program \\ in School Psychology
}

\author{
Fabíola de Sousa BRAZ-AQUINO' \\ Jéssica Andrade de ALBUQUERQUE ${ }^{1}$
}

\begin{abstract}
Resumo
Esse artigo aborda a experiência de estágio supervisionado em Psicologia Escolar desenvolvido em uma escola pública na cidade de João Pessoa (PB). A referida experiência foi norteada pela Psicologia Histórico-cultural de Vygotsky, que concebe as interações sociais enquanto pilares dos processos de aprendizado e formação da consciência dos sujeitos e a escola como espaço de mediação dos conhecimentos socio-historicamente organizados pela cultura. Os procedimentos adotados no estágio se concentraram na construção de relações com os atores institucionais, na apreensão do cotidiano escolar, na imersão nas práticas instituídas, bem como na assessoria aos docentes, equipe técnica e escolares. A partir dessa experiência verificou-se a relevância do estágio supervisionado para a construção de uma identidade do psicólogo que atuará em meios escolares, bem como para demarcar sua efetividade mediante processos de desenvolvimento humano em contextos públicos de educação.
\end{abstract}

Palavras-chave: Estágio supervisionado; Psicologia escolar; Teoria histórico-cultural.

\begin{abstract}
This article investigated a supervised internship program in School Psychology conducted in a public school in João Pessoa, PB, Brazil. This internship program was based on Vygotsky's Theory of Historical-cultural Psychology, who stresses that social interactions are imperative to cognitive and conscience development and that a school is as space for mediation of culturally organized social-historical knowledge. The internship program focused on the development of relationships with institutional actors, settling into the school routine, active participation in the assigned activities, and advising teachers, staff and students. This program indicated the importance of supervised internship for the construction of the identity of school psychologists and its effectiveness in processes that underlie human development in public educational settings.
\end{abstract}

Keywords: Supervised Internship; School psychology; Historical-cultural theory.

$\boldsymbol{\nabla} \nabla \boldsymbol{v}$

1 Universidade Federal da Paraíba, Departamento de Psicologia, Programa de Pós-Graduação em Psicologia Social. Campus Universitário I, s/n., Castelo Branco III, 58051-900, João Pessoa, PB, Brasil. Correspondência para/Correspondence to: F.S. BRAZ-AQUINO. E-mail: <fabiolabrazaquino@gmail.com>. 
O presente artigo aborda a experiência de Estágio Supervisionado Curricular em Psicologia Escolar realizado em um contexto de escola pública. As ações desenvolvidas durante o estágio compõem um percurso de formação acadêmico-científica que articulou a produção de conhecimentos advindos de disciplinas diretamente relacionadas à Psicologia Escolar Educacional, com pesquisas científicas (Albuquerque, 2013; Braz Aquino \& Albuquerque, 2014). Estas foram realizadas junto ao Núcleo de Estudos em Interação Social e Desenvolvimento Infantil (NEISDI) da Universidade Federal da Paraíba (UFPB), em nível de graduação e de pós-graduação.

O conjunto de pesquisas realizadas no NEISDI tem como marco teórico central o modelo histórico-cultural inaugurado por Vygotsky (1932/1996, 2000/1984, 2004/1982), para quem o desenvolvimento é um processo global e dinâmico que possui, em cada período, complexidade em sua organização e composição. Esse autor colocou em relevo a ideia de que a interação do sujeito com a cultura é parte constitutiva do desenvolvimento de habilidades tipicamente humanas.

Uma das inquietações de Vygotsky refere-se à explicação relativa à gênese e à história das funções psicológicas superiores que, segundo defendia, eram derivadas de um processo contínuo e dialético de mudanças provocadas pelas interações sociais, as quais se diferenciavam no homem por serem mediadas por um outro social mais experiente de uma cultura. O desenvolvimento dessas funções permite aos sujeitos, por exemplo, um pensamento abstrato e reflexivo, o uso intencional e generalizante da fala nas relações sociais e, ainda, a constituição da consciência, produto das relações concretas dos sujeitos com a cultura (Leontiev, 1982/2004).

Para Vygotsky (1984/2000), a explicação do desenvolvimento das funções psicológicas superiores está atrelada à análise da atividade prática ou laboral do homem mediada por instrumentos. Leontiev (1982/2004) relembra que esse autor "... destacava justamente o caráter específico que adquire a ação mediada por instrumentos nos processos psíquicos, sobretudo em sua determinação histórico-social no homem" (p.442). Pelo exposto, depreende-se a relevância do trabalho enquanto atividade consciente que pode alterar a relação do homem com seu contexto pelo caráter intencional, planejado e compartilhado. Influenciado pelo materialismo dialético de Marx (1867/1971), esse modelo retoma a ideia de que, pelo trabalho, o sujeito altera a natureza e, ao transformá-la, modifica sua relação com o meio ao engendrar processos tipicamente humanos (Leontiev, 1982/2004).

A relevância do trabalho para a constituição da hominização foi explicitada numa clássica analogia de Karl Marx na introdução ao texto "A consciência como problema da Psicologia do comportamento", do livro Teoria e Método em Psicologia de Vygotsky (1982/2004). Nessa citação, Marx (1867/1971) compara o trabalho de aranhas e abelhas ao do homem e argumenta que, neste último, a execução de uma obra é realizada no cérebro antes mesmo de iniciar seu processo, já que o homem constrói previamente um determinado objeto em sua mente. Esse tipo de ação sobre elementos da natureza não apenas muda a forma da matéria que aquela the oferece, mas "realiza nela seu objetivo" (Vygotsky, 1982/2004; p.55). Dito de outra forma, o que falta "na aranha e na abelha" é encontrado no homem devido a um longo processo de desenvolvimento filogenético que derivou uma ontogênese específica. Essas habilidades são sustentadas por um tipo de psiquismo que se reconfigura constantemente produzindo contornos cada vez mais sofisticados e complexos.

É fundamental pontuar que parte constitutiva desse processo repousa na historicidade e na cultura que originaram formas de atividade coletiva, as quais se tornaram complexas devido à interferência da fala, "... um fenômeno especial da cultura" (Leontiev, 1982/2004, p.480). Os significados que a fala e a palavra carregam, "... à semelhança dos instrumentos de trabalho, atuam como elemento intermediário entre a atividade do homem e o objeto externo, e servem de intermediários nas relações entre eles" (Leontiev, 1982/2004, p.480).

A partir dos escritos de Vygotsky e Luria (1930/1996), deriva-se a ideia de que as interações dos sujeitos com a cultura, incluindo aqui o contexto escolar, provocam um reequipamento, isto é, alte- 
ram suas "... formas de adaptação mais básicas ao mundo exterior" (p.214) e mobilizam transformações gradativas que favorecem a inserção de sujeitos menos experientes no mundo adulto cultural. Dessa forma, o trabalho, dotado de intencionalidade, modifica o tipo de relação que o homem estabelece com seu meio por seu caráter mediado e determinado historicamente. Nessa linha de raciocínio, as ações coletivamente organizadas e planejadas durante o estágio supervisionado em cursos de graduação estão diretamente articuladas às noções de trabalho enquanto atividade que deve refletir seu caráter consciente, intencional e mediado pela fala, expressa nos contextos institucionais pelos intercâmbios estabelecidos entre os sujeitos.

A escola, enquanto um contexto social que integra a vida das crianças e dos profissionais que nela se inserem, estabelece com os sujeitos uma relação complexa e única, marcada por diversidade de condições de aprendizado, atividades e práticas socioculturais. Vygotsky (1932/1996) argumentou que a relação da criança com o contexto social em cada idade é totalmente peculiar, específica e única. Esse tipo de relação do sujeito com o meio foi denominado pelo autor de Situação Social de Desenvolvimento, "... o ponto de partida para todas as trocas dinâmicas que se produzem no desenvolvimento durante o período de cada idade" (p.264).

Discutindo esse conceito, Mello (2010) coloca que a situação social de desenvolvimento engloba o conjunto de vivências as quais se traduzem enquanto unidade da relação imbricada entre as particularidades do sujeito e sua forma de representar cada vivência. De forma dinâmica e relativa, em cada etapa do desenvolvimento "não apenas a criança se modifica, modifica-se também a atitude do meio para com ela, e esse mesmo meio começa a influenciar a mesma criança de uma nova maneira" (Pino, 2010, p.750). Dito de outra forma, as relações e vivências das crianças em diferentes períodos do desenvolvimento podem colaborar para impulsionar mudanças no modo de estas perceberem seu entorno e atuarem sobre ele.

Discutindo o referido conceito, Souza, Petroni, Dugnani, Barbosa e Andrada (2014) afir- mam sua plausibilidade para compreender a escola e o trabalho do psicólogo escolar, levantando questionamentos em relação ao papel do contexto educativo na promoção de situações sociais de desenvolvimento e as possibilidades de vivências que se colocam para alunos e professores. Dessa forma, sustenta-se que a experiência do estágio, atrelada à concepção Vygotskyana de trabalho enquanto atividade compartilhada e intencionalmente pedagógica, pode engendrar processos de desenvolvimento humano em um movimento dialético que funcionaria como propulsor de novas relações no cenário escolar.

\section{Construindo pilares para a intervenção: procedimentos e percursos trilhados}

A experiência de estágio aqui relatada foi norteada, em linhas gerais, pela perspectiva institucional preventiva e relacional desenvolvida por Marinho-Araújo \& Almeida (2010), a qual se ancora em quatro dimensões: Mapeamento institucional; Espaço de escuta psicológica; Assessoria ao trabalho coletivo e Acompanhamento ao processo de ensino-aprendizagem. Nessa proposta, essas ações devem ocorrer simultaneamente articuladas à realidade e dinâmica da escola, contribuindo para reformulações pessoais e institucionais nesse contexto e para a criação de espaços de interlocução entre todos os agentes escolares.

Além da Intervenção institucional de Marinho-Araújo e Almeida (2010) e Marinho-Araújo (2014), recorreu-se ao modelo desenvolvido por Neves e Almeida (2003) e atualizado por Neves (2011), denominado "Procedimentos de Avaliação das Queixas Escolares e Níveis de Intervenção", o qual se organiza em três níveis de intervenção, quais sejam, escola, família e aluno. Nesses três níveis a participação direta do professor junto ao psicólogo é fundamental para entender as queixas escolares como "integradas ao processo histórico de cada indivíduo e às múltiplas interações sociais que ocorrem no contexto em que ele se insere" (Neves \& Marinho-Araújo, 2006, p.162).

As propostas de Neves (2011) e MarinhoAraújo (2014) defendem a adoção de uma pers- 
pectiva relacional, integradora e mais ampla, que objetiva intervir nas relações interpessoais, as quais se desdobram no processo de construção do conhecimento. Nesse sentido, o psicólogo escolar buscaria criar espaços de interlocuções entre os atores escolares na intenção de promover a conscientização de suas responsabilidades e papéis, bem como contribuir com discussões e sugestões para práticas que se alinhem às reais demandas educacionais (Marinho-Araújo \& Almeida, 2010).

Além das propostas de Marinho-Araújo \& Almeida (2010) e Neves (2011), percebeu-se como essencial a interlocução contínua com formulações e experiências de pesquisadores que se debruçaram sobre a atividade de estágio supervisionado, bem como sobre as possibilidades de articular, por meio dessa experiência, pressupostos teórico-metodológicos à práxis (Andrada, 2003, 2005; Galdini \& Aguiar, 2003; Guzzo, 2002, 2005, 2009, 2011; Guzzo, Mezzalira, Moreira, Tizzei, \& Silva Neto 2010; Machado, 2003, 2007, 2012; Martinez, 2003, 2005, 2010).

A atividade de estágio supervisionado no curso de Psicologia da UFPB é realizada nos dois últimos semestres da graduação ( $9^{\circ}$ e $10^{\circ}$ períodos), contabilizando 450 horas. Os critérios de inclusão para participar do estágio consistem na integralização de 226 créditos do curso, ter concluído todas as disciplinas dos conteúdos básicos da formação de psicólogo e cursado as de Estágio Supervisionado Básico I e ll. Após essa fase do curso, os estudantes devem optar por uma área de estágio, podendo escolher entre seis ênfases nas quais está incluída a Psicologia Educacional. No momento seguinte, os estagiários entram em contato com a supervisora e discutem, em linhas gerais, as possibilidades, a proposta geral da supervisora e as motivações do(a) graduando(a) para o trabalho no âmbito escolar.

No que se refere ao presente relato, o estágio foi iniciado com reuniões de supervisão as quais tinham como objetivo fomentar um adensamento teórico-metodológico das propostas desenvolvidas por estudiosos da área, bem como planejar os procedimentos para a inserção da estagiária no contexto educativo (Andrada, 2003, 2005; Costa \& Guzzo, 2006; Galdini \& Aguiar, 2003; Machado, 2003,
2007, 2012; Marinho-Araújo \& Almeida, 2010; Martinez, 2003, 2005, 2010; Meira \& Antunes, 2003; Silva Neto, Guzzo, \& Moreira, 2014; Neves, 2011). Nessa direção, foi proposto e construído um Protocolo de Mapeamento Institucional para nortear as primeiras ações a serem desenvolvidas na escola, visando uma articulação mais condizente com as demandas concretas que emergiriam no transcurso do estágio e a ampliação do olhar da estagiária sobre as possibilidades de ações no referido contexto (Andrada, 2003, 2005; Marinho-Araújo \& Almeida 2010; Martinez, 2010; Oliveira \& Marinho-Araújo, 2009; Souza, Petroni, \& Dugnani, 2011).

A partir da autorização da direção da escola para a realização do estágio, foi agendado um encontro entre a supervisora, a estagiária e a gestora escolar. Nessa reunião foi firmado o termo de compromisso e pactuada a participação da aluna nas reuniões pedagógicas, que são encontros quinzenais da equipe docente com duração média de uma hora, com a finalidade de discutir e planejar ações do processo de trabalho. Também foi concedida a permissão para conhecer projetos desenvolvidos pela equipe escolar e de extensão universitária realizados junto às turmas e, ainda, autorização para realizar a atividade de estágio durante quatro dias da semana em um turno completo. Essa modalidade de inserção visava à apreensão do cotidiano escolar, suas demandas e construção de relações entre os profissionais da instituição (Oliveira \& Marinho-Araújo, 2009). Buscou-se, assim, reafirmar a efetividade da atuação do psicólogo quando em parceria com a escola (Souza et al., 2014) e a relevância de uma participação ativa nas práticas institucionais para a construção de uma proposta afinada com a realidade da instituição (Costa \& Guzzo, 2006).

O estágio ocorreu numa escola pública de educação básica que abarcava creche, pré-escola e ensino fundamental I ( $1^{\circ}$ ao $5^{\circ}$ ano). Quando da inserção no contexto escolar, priorizou-se esclarecer a toda a equipe o papel do psicólogo na escola e como se daria essa atividade já na primeira reunião pedagógica, quando estava presente toda a equipe de professores. Nessa reunião foi apresentada a proposta da estagiária e distribuído um folder que 
explicitava a definição de Psicologia Escolar Educacional, as possibilidades de atuação do psicólogo escolar e os objetivos da atuação profissional nesse âmbito (Marinho-Araújo \& Almeida, 2010; Meira \& Antunes, 2003). Também foi distribuído um questionário direcionado aos docentes com a finalidade de levantar informações sobre o perfil dos profissionais e conhecer suas concepções acerca da profissão de educador, as expectativas sobre seu trabalho e sua rotina na escola.

Parte dos docentes presentes sinalizou uma compreensão sobre a prática do psicólogo na escola a qual remetia a um modelo clínico de atuação, representada na seguinte fala:

Ah! Pensei que você ia atender os alunos, mas tô vendo que é diferente. Vai ser uma coisa junta com a gente. No caso você vai ajudar a gente a entender coisas da Psicologia pra gente poder entender melhor as coisas dos meninos né isso? (Professora 1).

A análise desse extrato de fala reafirma a importância de resgatar o campo próprio da Psicologia Escolar por meio de práticas que respondam às demandas da educação e que promovam as qualidades positivas dos alunos e dos profissionais da instituição (Guzzo, 2002). Seguindo a proposta de Marinho-Araújo e Almeida (2010), foi realizado o mapeamento institucional (análise documental e investigação do contexto educativo), a partir do qual verificou-se que a escola possuía uma clientela diversificada e um quadro de profissionais que incluía pessoal técnico-administrativo, docentes (todos licenciados em Pedagogia e com pós-graduação diversificada), assistente social, coordenadora pedagógica, nutricionista e duas gestoras. É digno de menção que a escola onde ocorreu o estágio não tinha psicólogo em seu quadro de profissionais, nem experiência prévia com estagiários em Psicologia Escolar, embora esse profissional figurasse no Projeto Político Pedagógico (PPP) da instituição. Essas informações foram adquiridas por meio de análise documental, a qual permitiu conhecer o PPP, o regimento interno e os projetos em curso na escola.

Em conversa com os profissionais, verificou-se que não houve um trabalho coletivo que resultasse na construção do PPP vigente. Essa confi- guração reflete a ausência de um empenho conjunto dos atores escolares na construção coletiva desse documento, que deveria ser pautada em debates, diálogos e reflexões. O pouco envolvimento da equipe com o PPP também é consequência de uma incompreensão acerca de sua relevância como norteador das funções e ações da escola. Sobre a ausência do psicólogo na instituição escolar, estudiosos salientam a importância da participação desse profissional na construção e implantação do PPP, por favorecer a consolidação de sua profissão, bem como o aprimoramento da ação educativa (Martinez, 2003; Penteado \& Guzzo, 2010; Sant'Ana \& Guzzo, 2014; Wanderer \& Pedroza, 2010).

Para apreender o tipo de dinâmica relacional existente na escola e explorar de forma mais detalhada as principais demandas desse ambiente, foi instituído o espaço de escuta psicológica visando identificar as "vozes institucionais". Nessa proposta, a escuta é intencionalmente focada nos processos de ensino-aprendizagem e nas possibilidades de ressignificação de concepções e práticas dos profissionais (Marinho-Araújo, 2014; Neves, 2011; Neves \& Almeida, 2003). Além dessa ação, foi proposta pela estagiária a assessoria ao trabalho coletivo, caracterizada pela assistência ao corpo docente, à direção e à equipe técnica, visando colaborar para redimensionar o trabalho dos professores e fomentar práticas intencionalmente pedagógicas. Outra ação que figurou na proposta de estágio foi o Acompanhamento do Processo de Ensino-Aprendizagem que, na presente experiência, materializou-se através de observações em sala de aula e levantamento das produções das crianças, atrelados aos encontros constantes com os professores (Marinho-Araújo, 2014; Marinho-Araújo e Almeida, 2010; Oliveira \& Marinho-Araújo, 2009). Essas ações do psicólogo escolar também foram destacadas por pesquisadores como Andrada (2005), Guzzo (2002, 2005), Machado (2003, 2007, 2012), Martinez (2003, 2010) e Souza et al. (2011, 2014), que defendem uma perspectiva de atuação abrangente e focada na parceria com o coletivo da escola.

Concomitantes a essas ações e derivadas dos registros em diário de campo - instrumento que reunia o conjunto de informações levantadas pela 
estagiária em sua prática na escola -, foram ressaltadas as inquietações por parte das docentes em relação às insatisfações sobre suas condições de trabalho, às incertezas relativas ao vínculo trabalhista e às dificuldades no relacionamento com as famílias das crianças. De acordo com Marinho-Araújo e Almeida (2010), o docente, de maneira geral, sofre a tensão que se coloca na escola e os sentimentos de insatisfação profissional podem se instaurar por não conseguirem cumprir as exigências a eles demandadas no campo profissional. Por isso, esses sentimentos devem ser analisados como parte do contexto escolar, uma vez se que refletem dialeticamente na prática educativa e nas relações em sala de aula (Neves, 2011). Parte das queixas docentes incluía ainda dificuldades na prática, como o modo de atuar durante o processo de adaptação e o retorno das crianças após o período de férias. Essa demanda mobilizou o planejamento de uma conversa da estagiária com as docentes acerca de fatores relacionados à adaptação das crianças à creche, bem como a distribuição de um folder contendo esclarecimentos e sugestões sobre esse processo (Rapaport \& Piccinini, 2001; Rosseti-Ferreira, Vitoria, \& Goulardins, 1998; Santos, 2012). A partir dessa ação, outros docentes procuraram a estagiária para referir queixas sobre indisciplina, bullying e preconceito.

Já as observações em sala de aula concentraram-se na apreensão da dinâmica da relação professor-aluno, nos procedimentos pedagógicos adotados pelos professores e no modo como as crianças interagiam entre si e com o professor diante das atividades propostas. Por meio dessas observações, registros em diário de campo e conversas com os professores, foram levantados indicadores de suas percepções acerca do desenvolvimento e aprendizagem dos escolares, dos processos de avaliação e das concepções sobre o trabalho que exerciam.

Após a realização dessas observações, houve encontros com as docentes para expor os elementos identificados. Notou-se que esses espaços para diálogo com as professoras permitiu a construção de uma relação colaborativa entre as docentes e a estagiária, pautada em uma postura propositiva que do psicólogo escolar, como expressado na fala a seguir: "... . Pensava que só ia ouvir crítica. Tô feliz em ouvir que faço coisas boas. Isso é raro! [risadas]" (Professora 1). Paralelamente a esses encontros, a estagiária solicitou à gestora a participação na reunião pedagógica para expor o levantamento realizado.

Nessa reunião, priorizou-se evidenciar os aspectos considerados favoráveis à relação professor-aluno, como o envolvimento do docente com seu trabalho, a existência de uma relação afetuosa entre professores e alunos e a abertura da escola à proposta de estágio. Em seguida, foram colocados elementos relativos à prática pedagógica, à relação professor-aluno, aluno-aluno e família-escola, demandas que emergiram no conjunto de informações recolhidas.

Foram discutidas as práticas pedagógicas pontuais que poderiam funcionar como entraves do processo de ensino-aprendizagem, quais sejam, uso de tarefas repetidas; aulas geralmente expositivas com pouca participação dos estudantes; ausência de correção coletiva das tarefas escolares; atitudes coercitivas com os alunos frente aos exercícios escolares; e utilização das tarefas como forma de punição para comportamentos não desejáveis das crianças. A abordagem utilizada nesse ponto concentrou-se na imagem do professor enquanto agente fundamental no favorecimento do processo de aprendizagem do aluno, desmistificando a ideia de que as queixas escolares têm suas causas situadas em um dos membros de uma relação.

Os docentes se posicionaram positivamente no que diz respeito à estratégia utilizada pela aluna na exposição do material recolhido, como se segue: "... . Geralmente se coloca que estamos errando, que precisamos melhorar, mas ninguém se dispõe a fazer diferente com a gente. Isso é o que eu tô mais gostando nesse seu estágio, que pra gente é uma coisa nova" (Professora 2).

As falas das Professoras 1 e 2, indicam a relevância da mediação do estagiário para provocar reflexões acerca das concepções dos docentes sobre seu trabalho, aqui entendido como uma produção compartilhada, dialética e coletiva, marcada por tensões e desafios. Cabe lembrar que as contra- 
dições e embates gerados pelas relações estabelecidas na escola se constituem, a partir do modelo histórico-cultural, na "força motora do desenvolvimento" (Leontiev, 1982/2004, p.445).

Dessa forma, a assessoria do psicólogo deve colaborar com a produção de um trabalho pedagógico consciente e que reflita condições materiais e históricas do grupo para o qual e com o qual trabalha, na perspectiva de promover a socialização dos conhecimentos socioculturalmente organizados. A partir da perspectiva Vygotskyana, afirma-se que o instrumento da fala, enquanto "fenômeno cultural" e mediador das relações entre os profissionais e a estagiária (Vygotsky, 1982/2004), se interpôs como um vetor para superação de um cenário escolar que demandava mudanças nas relações instituídas.

Ao término da exposição na reunião pedagógica, três professoras mencionaram estar dispostas a participar da assessoria proposta pela estagiária. Em continuidade, foram agendados encontros individuais com cada professora, a fim de planejar as ações em suas respectivas salas de aula. Para explicitar como as intervenções se materializaram na escola, é relatada a seguir a experiência vivenciada.

\section{Intervenções junto aos docentes e estudantes: iniciando uma parceria}

O trabalho de intervenção foi realizado em duas vertentes: a assessoria aos docentes e o trabalho em sala de aula envolvendo alunos e professores. No total foram feitos oito encontros individuais com três docentes e três inserções em suas respectivas salas de aula (turmas do pré-escolar II e do primeiro ano do ensino fundamental I). Os encontros ocorreram semanalmente e foram subsidiados por leituras de textos previamente disponibilizados, na perspectiva de fomentar um novo entendimento acerca das demandas levantadas e a gradativa apreensão por parte das docentes da relevância de um trabalho intencionalmente pedagógico realizado com as crianças. Buscava-se, pela via da conscientização do professor enquanto mediador de conceitos científicos, construir propostas de intervenção focadas nas relações interpessoais e nos processos de ensino e aprendizagem, visando à totalidade institucional (Galdini \& Aguiar, 2003).

No trabalho de assessoria retomava-se o que os professores haviam apreendido por meio das leituras dos textos disponibilizados, suas impressões sobre o impacto destas nas atividades em sala com as crianças, além de serem discutidas sugestões do uso de ferramentas mediadoras para a continuidade do trabalho. É importante mencionar que as atividades planejadas durante esses encontros estavam atreladas aos conteúdos e projetos desenvolvidos pelas docentes em cada turma e coadunadas com a dinâmica das salas de aula.

Como parte dos procedimentos de intervenção foram utilizados vídeos, slides, narrativas de contos, fantoches, produção de cartazes, desenhos e músicas infantis como forma de acessar as vivências de diversos segmentos da comunidade escolar. Concebidas por Souza et al. (2011) enquanto materialidades medidoras, essas ferramentas constituem símbolos da cultura utilizados para acessar a subjetividade dos sujeitos "... . Favorecendo sua expressão e promovendo o desenvolvimento da consciência de si e do outro" (p.265). A escolha desses recursos ampara-se na concepção de Vygotsky (1987/1998), para quem a arte possibilita o acesso à subjetividade e permite a atribuição de novos significados e sentidos ao que é proposto, representando um elemento mediador da expressão dos sujeitos.

As intervenções em sala de aula se concentraram no trabalho com os professores e alunos sobre as queixas referidas pelos docentes, como o desrespeito entre pares, o preconceito em relação à cor e às crianças com alguma deficiência, o descrédito dos alunos frente às capacidades dos colegas e as conversas paralelas durante a exposição dos conteúdos. No início de cada intervenção, a estagiária fazia um rearranjo na disposição das carteiras dos estudantes para que estes ficassem posicionados em círculos a fim de facilitar a interação e o debate.

Em uma das ocasiões foi exibido em data show um vídeo da Turma da Mônica que abordava o preconceito. Na história, todos os personagens eram azuis, exceto um deles. Durante a exibição, as crianças verbalizavam suas impressões: "ninguém 
quer brincar com ela porque ela não é azul"; "tadinha da Mônica... se eu tivesse lá eu brincava com ela". Após concluída a exibição, a estagiária e a professora lançavam perguntas que disparavam o debate junto ao grupo de crianças.

Em outra oportunidade, foi realizada a atividade denominada "corrente de papel", a qual consiste na arte de cortar de uma só vez o papel dobrado e abri-lo para revelar um determinado padrão. Visando trabalhar o respeito à diversidade, cada criança foi incentivada a produzir e decorar sua corrente de papel em forma de pessoa. Essa produção individual, no coletivo, visou provocar nas crianças a reflexão e a discussão sobre como as pessoas podem ser diferentes, confrontando-as mais uma vez com a questão do preconceito e da diversidade. Em resposta a essa vivência, os alunos proferiram comentários diversos os quais sinalizavam novos sentidos sobre "ser diferente": "Eu entendi que diferença não é nada de mais"; "Aqui na sala tem gente da cor de chocolate, tem gordo, tem magro e nenhum é mais melhor"; "A gente tá brincando com todos os colegas e eles tão alegres e a gente também porque quando respeita todo mundo fica feliz". Tudo isso indica uma resignificação da questão do preconceito.

No último momento dessa inserção foi realizada a atividade de recorte e colagem para problematizar a demanda correspondente ao preconceito e o respeito à diversidade. Essa atividade foi construída por meio de conversas entre a professora, a estagiária e as crianças e visava provocar conscientização sobre a importância do respeito ao próximo.

Em outra intervenção foi narrada a história "O peixinho de chocolate" de Mendonça (2000). Após esse momento, as crianças explicitaram suas impressões e sentimentos com relação à história e construíram, coletivamente, um cartaz sobre o respeito às diferenças. Este foi fixado no pátio da escola para que toda a comunidade escolar pudesse visualizar e discutir.

Ao longo de todo esse percurso, foram criadas condições para que as crianças apresentassem seus pontos de vista acerca das temáticas em discussão, tendo como ferramentas recursos lúdicos e artísticos. As falas dos alunos eram utilizadas como propulsoras de diálogo e, a partir delas, buscava-se problematizar as atitudes preconceituosas e o desrespeito entre o grupo, demanda apontada pelas docentes. Entende-se que essas atividades oportunizaram a circulação da fala do outro acerca de suas produções e vivências em cada período de idade, bem como favoreceram a atribuição de significados e a construção de sentidos (Souza et al., 2011).

Após a realização das intervenções, foram discutidos com os docentes os possíveis impactos e efeitos provocados. Segundo uma delas:

O resultado foi muito positivo, inclusive colegas de outras salas disseram que notaram que os meninos tão convidando os coleguinhas que ficavam excluidos. Mas eu sei que tem que ser uma coisa contínua, porque eu já havia em outros momentos conversado com eles sobre isso e eles demonstravam que iam melhorar, mas quando o tempo se passava eles voltavam às mesmas atitudes... . Eu entendo que vai requerer empenho meu nesse sentido (Professora 3).

A partir da fala acima, entende-se que a consciência dos profissionais sobre si e sobre seu trabalho pode mobilizar transformações na direção de ações promotoras de desenvolvimento. Uma análise crítica permite afirmar a necessidade de um trabalho contínuo de assessoria aos docentes o qual permita intercâmbios fundamentados teoricamente, na perspectiva de reverter cenários onde se expressem comportamentos discriminatórios entre as crianças e os diversos atores da comunidade escolar.

No momento final do estágio foi solicitado à gestora da instituição um espaço na reunião pedagógica para expor o trabalho realizado com os professores e suas respectivas turmas. Nessa reunião, a gestora mencionou que conseguiu perceber como é o trabalho do psicólogo na escola, embora ainda tivesse como expectativa o atendimento individual aos alunos. Também as docentes se posicionaram em relação à experiência com o estágio em Psicologia Escolar:

Como nunca tivemos estagiária nem profissional de Psicologia aqui, no começo confesso que idealizei outra forma de trabalho, 
mas achei bastante proveitosa a maneira que tudo foi conduzido. Tudo planejado, sempre embasado em teorias. Enfim, foi muito bom. Pena que não estará aqui pra continuarmos dividindo experiências, pois me senti muito confortável com você (Professora 2).

Outra docente mencionou:

A gente que não esteve com você sempre, percebemos um movimento diferente na escola. Não é comum o professor se sentar com estagiária pra discutir, pra planejar. Acho que seria bom outros estagiários de Psicologia aqui pra continuar seu trabalho (Professora 3).

Percebeu-se que a experiência de estágio gerou inquietações nos profissionais da escola, expressas pelo fato de os mesmos solicitarem constantemente esclarecimentos em torno das ações sugeridas pela estagiária. Entende-se que esse fato está associado ao caráter inaugural da proposta adotada, a qual exige tempo e envolvimento por parte da comunidade escolar. Por outro lado, deve-se ressaltar que, desde o início, houve abertura e colaboração de todo o pessoal da instituição, o que viabilizou a proposta apresentada à equipe e aos docentes.

\section{Considerações Finais}

Neste artigo, foi apresentado um relato de experiência de estágio supervisionado em uma escola pública da cidade de João Pessoa (PB). A vivência aqui relatada objetivou mobilizar, marcadamente nos profissionais, processos de desenvolvimento humano e aprendizado frente às demandas emergentes nesse contexto. As reflexões advindas dessa experiência permitem afirmar que a mediação da estagiária mostrou-se inaugural para a comunidade escolar, o que permitiu uma maior compreensão e visibilidade do papel do psicólogo nesse espaço, ainda amplamente desconhecido pela sociedade e pelos profissionais da educação.

Com apoio nos pressupostos Vygotskyanos, defende-se que, a despeito das contradições, da historicidade e da complexidade que revestem cada instituição escolar pública brasileira, a vivência do estágio deve mobilizar uma conscientização do pa- pel do trabalho do estagiário e futuro psicólogo e a ressignificação de concepções e práticas dos diversos atores imersos nesses contextos. Nesse sentido, durante o percurso do estágio, buscou-se aprofundar o conhecimento acerca da dinâmica escolar e de que modo os sujeitos mais experientes poderiam interferir para a gradativa apropriação, pelos escolares, dos conhecimentos sistematizados e organizados de uma cultura.

Defende-se que, alinhada a esse modelo, a atividade de estágio, ao permitir uma imersão prévia no contexto escolar, oportuniza a apropriação de ferramentas teórico-metodológicas que colaboram para a construção de respostas às demandas e complexidades desse cenário. Além disso, espera-se que os conhecimentos advindos da formação em Psicologia se articulem com as necessidades concretas e historicamente construídas no interior das escolas.

Nessa direção, considera-se que o entendimento e a parceria da comunidade escolar acerca do trabalho do psicólogo são forjados, desde a formação básica na graduação, pela inserção em grupos de pesquisa e extensão e pela experiência de estágio supervisionado que, em consonância, favorecem o desenvolvimento de competências específicas para a atuação do psicólogo em contextos educacionais. No que se refere à tarefa de narrar essa vivência, considera-se relevante mencionar a complexidade em traduzir uma experiência pela via da produção escrita, dado que esta sempre deixa escapar aquilo que foi vivenciado no cotidiano com o recurso da fala, a qual potencializa os movimentos e as tensões presentes nas relações.

É digno de menção que os procedimentos adotados durante as intervenções foram facilitados pelo uso de "mediadores estéticos", como atividades plásticas, recursos audiovisuais e narrativas infantis, os quais permitiram captar as vivências e demandas específicas dos envolvidos na proposta. Essas ferramentas possibilitaram, ainda, o exercício contínuo e dialético de ação-reflexão-ação sobre o trabalho desenvolvido.

Com o amparo de pesquisas do campo da Psicologia Escolar Educacional, reafirma-se que a ênfase da proposta residiu, sobretudo, no fomento da autonomia e empoderamento do docente e do coletivo da escola. Nesse aspecto, resgata-se a ideia 
de Martín-Baró (1996), para quem a escola e o trabalho do psicólogo deveriam estar pautados na "desalienação das pessoas e grupos, que as ajude a chegar a um saber crítico sobre si próprias e sobre sua realidade" (p.17). Ainda segundo esse autor, o trabalho do psicólogo deve permitir confronto dos fatores sociais onde se materializa a subjetividade.

Com efeito, ressalta-se que a experiência de estágio supervisionado demarca a importância da presença efetiva do psicólogo na composição do quadro de pessoal das escolas. Além disso, sua presença favorece o aprimoramento profissional frente à qualidade das respostas educativas e o entendimento da comunidade escolar acerca da gama de ações que podem ser implementadas por ele em parceria com toda a equipe. Por fim, sustenta-se como relevante a formação continuada de psicólogos que estejam atuando em meios educacionais, aliada ao desenvolvimento de pesquisa-intervenção realizada em nível de pós-graduação, na perspectiva de construir um arcabouço teórico-metodológico que promova transformações de práticas tradicionais instituídas e fomente a promoção de desenvolvimento humano.

\section{Colaboradores}

Todos os autores contribuíram na concepção e desenho do estudo, análise de dados e redação final.

\section{Referências}

Albuquerque, J. A. (2013). Percepções de crianças do $4^{\circ}$ e $5^{\circ}$ anos do ensino fundamental sobre a escola. Anais do XXI Encontro de Iniciação Científica da Universidade Federal da Paraíba, João Pessoa.

Andrada, E. G. C. (2003). Família, escola e a dificuldade de aprendizagem: intervindo sistemicamente. Psicologia Escolar e Educacional, 7(2), 171-178.

Andrada, E. G. C. (2005). Novos paradigmas na prática do psicólogo escolar. Psicologia: Reflexão e Crítica, 18(2), 196-199.

Braz Aquino, F. S., \& Albuquerque, J. A. (2014). O que pensam e sentem as crianças sobre a escola? Uma análise de relatos e desenhos infantis. In R. S. L Guzzo (Org.), Psicologia Escolar: desafios e bastidores na educação pública (pp.55-83). Campinas: Alínea.
Costa, A. S., \& Guzzo, R. S. L. (2006). Psicólogo escolar e educação infantil: um estudo de caso. Revista Escritos sobre Educação, 5(1), 5-12.

Galdini, V., \& Aguiar, W. M. J. (2003). Intervenção junto a professores da rede pública: potencializando a produção de novos sentidos. In M. E. M. Meira \& M. A. M. Antunes (Orgs.), Psicologia Escolar: práticas críticas (pp.87-103). São Paulo: Casa do Psicólogo.

Guzzo, R. S. L. (2002). Novo paradigma para a formação e atuação do psicólogo escolar no cenário educacional brasileiro. In R. S. L. Guzzo (Org.), Psicologia Escolar: LDB e educação hoje (pp.131-144). Campinas: Alínea.

Guzzo, R. S. L. (2005). Escola amordaçada: compromisso do psicólogo com este contexto. In A. M. Martínez (Org.), Psicologia Escolar e compromisso social: novos discursos, novas práticas (pp.17-29). Campinas: Alínea.

Guzzo, R. S. L. (2009). O debate e os caminhos do ano da educação: revivendo as necessidades e possibilidades. In Seminário Nacional do ano da educação - Psicologia: profissão na construção da educação para todos (pp.40-47). Brasília: Conselho Federal de Psicologia.

Guzzo, R. S. L. (2011). Desafios cotidianos em contextos educativos: a difícil formação de psicólogos para a realidade brasileira. In R. G. Azzi \& M. H. T. A. Gianfaldoni (Orgs.), Psicologia e Educação (pp.253-270). São Paulo: Casa do Psicólogo.

Guzzo, R. S. L., Mezzalira, A. S. C., Moreira, A. P. G., Tizzei, R. P., \& Silva Neto, W. M. F. (2010). Psicologia e educação no Brasil: uma visão da história e possibilidades nessa relação. Psicologia: Teoria e Pesquisa, 26(Esp.), 131-141.

Leóntiev, A. N. (2004). Artigo de introdução sobre o trabalho criativo de L. S. Vigotski, por A. N. Leóntiev. In L. S. Vygotsky. Teoria e método em Psicologia (3a ed.). São Paulo: Martins Fontes. (Originalmente publicado em 1982).

Machado, A. M. (2003). Os psicólogos trabalhando com a escola: intervenção a serviço do quê? In M. E. M. Meira \& M. A. M. Antunes (Orgs.), Psicologia Escolar: práticas críticas (pp.63-85). São Paulo: Casa do Psicólogo.

Machado, A. M. (2007). Avaliação psicológica na educação: mudanças necessárias. In E. Tanamachi, M. Proença, \& M. Rocha (Orgs.), Psicologia e educação: desafios teórico-práticos (pp.143-167). São Paulo: Casa do Psicólogo.

Machado, A. M. (2012). Formas de pensar e agir nos acontecimentos escolares: criando brechas com a Psicologia. In M. G. D. Facci, M. E. M. Meira, \& S. C. Tuleski (Orgs.), A exclusão dos "incluídos": uma crítica da Psicologia da Educação à patologização e medicalização dos processos educativos ( ${ }^{a}$ ed., pp.53-74). Maringá: Eduem.

Marinho-Araújo, C. M. (2014). Intervenção institucional: ampliação crítica e política da atuação em Psicologia Escolar. In R. S. L. Guzzo (Org.), Psicologia Escolar: de- 
safios e bastidores na educação pública (pp.153-175). Campinas: Alínea.

Marinho-Araújo, C. M. M., \& Almeida, S. F. C. (2010). Psicologia Escolar: construção e consolidação da identidade profissional. Campinas: Alínea.

Martín-Baró, I. (1996). O papel do psicólogo. Estudos de Psicologia (Natal), 2(1), 7-27.

Martinez, A. M. (2003). O psicólogo na construção da proposta pedagógica da escola: áreas de atuação e desafios para a formação. In S. F. C. Almeida (Org.), Ética e competências na formação e atuação profissional (pp.105-124). Campinas: Alínea.

Martinez, A. M. (2005). Psicologia Escolar e compromisso social. Campinas: Alínea.

Martinez, A. M. (2010). O que pode fazer o psicólogo na escola? Em Aberto, 23(83), 39-56.

Marx, K. (1971). O capital: crítica da economia política. Livro 1: o processo de produção capitalista ( $2^{a}$ ed.). Rio de Janeiro: Civilização Brasileira. (Trabalho originalmente publicado em 1867).

Meira, M. E. M., \& Antunes, M. A. M. (2003) (Orgs.). Psicologia Escolar: práticas críticas. São Paulo: Casa do Psicólogo.

Mello, S. A. (2010). A questão do meio na pedologia e suas implicações pedagógicas. Psicologia USP, 21(4), 727-739.

Mendonça, C. (2000). O peixinho de chocolate. Uberlândia: Fotolito.

Neves, M. M. B. J. (2011). Queixas escolares: conceituação, discussão e modelo de atuação. In R. S. L. Guzzo \& C. M. Marinho-Araújo (Orgs.), Psicologia Escolar: identificando e superando barreiras (pp.175-214). Campinas: Alínea.

Neves, M. M. B. J., \& Almeida, S. F. C. (2003). A atuação da Psicologia Escolar no atendimento aos alunos encaminhados com queixas escolares. In S. F. C. Almeida (Org.), Psicologia Escolar: ética e competência na formação e atuação profissional (pp.83-103). Campinas: Alínea.

Neves, M. M. B., \& Marinho-Araújo, C. M. (2006). A questão das dificuldades de aprendizagem e o atendimento psicológico às queixas escolares. Aletheia, 24, 161-170.

Oliveira, C. B. E., \& Marinho-Araújo, C. M. (2009). Psicologia Escolar: cenários atuais. Estudos e Pesquisas em Psicologia, 9(3), 648-663.

Penteado, T. C. Z., \& Guzzo, R. S. L. (2010). Educação e Psicologia: a construção de um projeto político-pedagógico emancipador. Psicologia \& Sociedade, 22(3), 569-577.

Pino, A. (2010). A criança e seu meio: contribuição de Vygotsky ao desenvolvimento da criança e à sua educação. Psicologia USP, 21(4), 741-756.

Rapaport, A., \& Piccinini, C. A. (2001). O ingresso e adaptação de bebês e crianças pequenas à creche: alguns aspectos críticos. Psicologia: Reflexão e Crítica, 14(1), 81-95.

Rosseti-Ferreira, M. C., Vitoria, T., \& Goulardins, L. G. (1998). Quando a criança começa a frequentar a creche ou pré-escola. In M. C. Rosseti-Ferreira (Org.), Os fazeres na educação infantil (pp.43-47). São Paulo: Cortez.

Sant'Ana, I. M., \& Guzzo, R. S. L. (2014). O psicólogo escolar e o projeto político-pedagógico da escola: diálogos e possibilidades de atuação. In R. S. L. Guzzo (Org.), Psicologia Escolar: desafios e bastidores na educação pública (pp.85-109). Campinas: Alínea.

Santos, E. P. (2012). Adaptação de crianças na educação infantil. Revista e-Ped-FACOS, 2(1), 30-39.

Silva Neto, W. M. F. S., Guzzo, R. S. L., \& Moreira, A. P. G. (2014). Estagiários de Psicologia na escola: o que os bastidores revelam para a formação profissional? In R. S. L. Guzzo (Org.), Psicologia Escolar: desafios e bastidores na educação pública (pp.197-216). Campinas: Alínea.

Souza, V. L. T., Petroni, A. P., \& Dugnani, L. A. C. (2011). $A$ arte como mediação nas pesquisas e intervenção em Psicologia Escolar. In R. S. L. Guzzo \& C. M. Marinho-Araújo (Orgs.), Psicologia Escolar: identificando e superando barreiras (pp.261-285). Campinas: Alínea.

Souza, V. L. T., Petroni, A. P., Dugnani, L. A. C, Barbosa, E. T., \& Andrada, P. C. (2014). O psicólogo na escola e com a escola: a parceria como forma de atuação promotora de mudanças. In R. S. L. Guzzo (Org.), Psicologia Escolar: desafios e bastidores na educação pública (pp.27-54). Campinas: Alínea.

Wanderer, A., \& Pedroza, R. L. S. (2010). Elaboração de projetos político-pedagógicos: reflexões acerca da atuação do psicólogo na escola. Revista Semestral da Associação Brasileira de Psicologia Escolar e Educacional, 14(1), 121-129.

Vygotsky, L. S. (1996). El problema de la edade. In Obras Escogidas IV: Psicología infantil (pp.251-276). Madrid: Visor. (Originalmente publicado en 1932).

Vygotsky, L. S. (1998). Pensamento e linguagem. São Paulo: Martins Fontes. (Originalmente publicado em 1987).

Vygotsky, L. S. (2000). A formação social da mente. São Paulo: Martins Fontes. (Originalmente publicado em 1984).

Vygotsky, L. S. (2004). Teoria e método em Psicologia (3a ed.). São Paulo: Martins Fontes. (Originalmente publicado em 1982).

Vygotsky, L. S., \& Luria, A. R. (1996). Estudos sobre a história do comportamento: símios, homem primitivo e criança. Porto Alegre: Artes Médicas. (Originalmente publicado em 1930).

Recebido: novembro 30, 2015

Aprovado: dezembro 21, 2015 
